\title{
ANNE-LISE DELACRÉTAZ, Catherine Colomb. En plein et lointain avenir
}

\section{Elisa Borghino}

\section{OpenEdition}

\section{Journals}

\section{Edizione digitale}

URL: https://journals.openedition.org/studifrancesi/45418

DOI: 10.4000/studifrancesi.45418

ISSN: 2421-5856

\section{Editore}

Rosenberg \& Sellier

\section{Edizione cartacea}

Data di pubblicazione: 1 août 2021

Paginazione: 399

ISSN: 0039-2944

\section{Notizia bibliografica digitale}

Elisa Borghino, «AnNE-LISE delACRÉtAz, Catherine Colomb. En plein et lointain avenir», Studi Francesi [Online], 194 (LXV | II) | 2021, online dal 01 septembre 2021, consultato il 15 octobre 2022. URL: http:// journals.openedition.org/studifrancesi/45418 ; DOI: https://doi.org/10.4000/studifrancesi.45418

Questo documento è stato generato automaticamente il 15 octobre 2022.

\section{(2) $\Theta \Theta \Theta$}

Creative Commons - Attribuzione - Non commerciale - Non opere derivate 4.0 Internazionale - CC BY NC-ND 4.0

https://creativecommons.org/licenses/by-nc-nd/4.0/ 


\title{
ANNE-LISE DELACRÉTAZ, Catherine Colomb. En plein et lointain avenir
}

\author{
Elisa Borghino
}

\section{NOTIZIA}

ANNE-LISE DELACRÉTAZ, Catherine Colomb. En plein et lointain avenir, Savoir Suisse, 2019, 168

pp.

1 È il 1929 quando Virginia Woolf scrive di «una stanza tutta per sé». E di una «stanza minuscola, tutta per lei, con un divano, una libreria, una scrivania» racconta tre anni dopo Catherine Colomb. Come la scrittrice inglese, la "romanziera geniale" che nel 1951 entusiasma Jean Paulhan è stata spesso giudicata per il suo stream of consciousness, talvolta anche paragonata agli autori del Nouveau Roman.

2 Tormentata dal ricordo di un'infanzia difficile, Catherine Colomb ha saputo prendere spunto dalla propria memoria per dare vita ad una scrittura lirica ed ironica al tempo stesso. Lucida e determinata, l'ex-bambina ferita è pienamente cosciente della complessità della sua opera. Ed è così che, con molta ironia e consapevolezza, commenta le critiche ai suoi romanzi nel giugno 1964. Tra le sue riflessioni, quelle sulla memoria e sulla vita tutta intera, che raccoglie ricordi, visioni e sogni, e quelle sulla città di Losanna, dove completa i suoi studi e riprende a creare, a vivere. Gli anni della formazione vedono delinearsi con maggiore chiarezza gli interessi professionali; ma saranno la paura del futuro e il venir meno della rendita mensile lasciatale dalla zia a spingerla a cercare lavoro presso redattori ed editori di Losanna, dando il via ad un decennio ricco di esperienze e di progetti, benché segnato dalle difficoltà e dalle incertezze della guerra.

3 La discrezione assoluta nella quale compone un'opera tanto esigente quanto affascinante la renderanno un personaggio misterioso, che continua ad alimentare un numero sempre maggiore di ricerche incentrate sulla sua figura. Varie generazioni di critici, ricercatori e tesisti hanno accompagnato negli anni la sua opera: da Gustave 
Roud a Philippe Jaccottet, da Éric de Montmollion a Jeanlouis Cornuz, e ancora Jean Paulhan, Jean-Luc Seylaz, Pierre-André Rieben et José-Flore Tappy, come ci ricorda Delacrétaz nella sua monografia. Nomi di rilievo nel panorama letterario internazionale, che hanno saputo avvicinarsi ad una scrittura dalla profonda audacia e dalla spiccata originalità. Un lavoro rigoroso di lettura e documentazione che coinvolge tuttavia solo una quindicina di quaderni e taccuini sfuggiti alla distruzione: la leggenda famigliare narra infatti della sua abitudine di bruciare nella stufa la brutta copia dei suoi romanzi. Quaderni e taccuini che testimoniano tanto le ricerche sul romanticismo tedesco e gli studi sul discorso diretto e indiretto libero, quanto la passione per il lavoro a maglia, con modelli di babbucce e calzamaglia per i nipotini.

4 L'apertura degli archivi nel 2014 ha permesso così l'accesso ad una ricca corrispondenza con Gustave Roud et Ottoline Morrell, oltre che con famigliari e amici, e facilitato la scoperta di una donna discreta, riservata, dalla formazione intellettuale eccezionale in un cantone ancora restio a promuovere l'istruzione universitaria delle donne. 